\title{
LCI Modelling approaches applied on recycling of materials in view of environmental sustainability, risk perception and eco-efficiency
}

\author{
Rolf Frischknecht ${ }^{1}$ \\ 1 ecoinvent Centre, Empa, $\mathrm{CH}-8600$ Dübendorf, Switzerland \\ Speaker: Rolf Frischknecht \\ Corresponding author: Rolf Frischknecht, frischknecht@ecoinvent.org
}

\begin{abstract}
Two ISO-compatible approaches on modelling the recycling of plastics and metals are frequently applied in life cycle assessment case studies and intensively debated: the recycled content or cut-off approach and the end of life recycling or avoided burden approach. This paper discusses the two approaches from three different perspectives: 1) the kind of sustainability concept served, 2) the risk perception involved and 3) the eco-efficiency indicators resulting from the two approaches. The analysis shows that the recycled content approach serves the strong sustainability concept. It is based on a risk aversive attitude and results in higher eco-efficiency of metal scrap recycling as compared to primary metal manufacture. The end of life recycling approach serves the weak sustainability concept (losses in natural capital can be compensated by man-made capital). It corresponds to a risk seeking attitude and results in higher eco-efficiency of primary metal manufacture as compared to secondary metal production. It is concluded that a harmonisation of the approaches is hardly possible and even not necessary due to the value choices involved. It is the task of (private and public) LCA commissioners to decide on the appropriate modelling approach according to their perspective. National authorities may have a rather long-term and risk aversive perspective while industries may prefer a short term perspective leading them to select the recycled content and end of life recycling approach respectively. Life cycle inventory databases need to be flexible to serve such opposing perspectives and to enable practitioners to adapt the modelling approaches according to the needs of the commissioner. Flexibility is served best by providing unit process $\mathrm{LCl}$ data.
\end{abstract}

Keywords: Cut-off, avoided burdens, sustainability concepts, risk perception, eco-efficiency, life cycle inventory

\section{Introduction and Theses}

The life cycle inventory modelling of recycling of materials and in particular of metals is currently very much debated. Recent publications on this issue comprise for instance KLÖPFFER (1996), KIM ET AL. (1997), FRISCHKNECHT (2000), WEIDEMA (2001), WERNER (2002), EKVALL \& WEIDEMA (2004), YAMADA ET AL. (2006), ANONYMOUS (2006), and FRISCHKNECHT (2006). The proposed methodologies can roughly be classified into two distinctly different approaches that are currently used in daily LCA practice:

- recycled content approach (also known as the cut-off approach), and

- $\quad$ end of life recycling approach (also known as the avoided burden approach). 
Their usefulness and appropriateness have been discussed with regard to several aspects such as the promotion of the use of recycled materials, the support of design for recycling, or the operationalization of the precautionary principle.

The paper starts from the thesis that the goal of an LCA study does not automatically determine the appropriate modelling approach. The modelling approaches involve value choices and thus other criteria to choose the appropriate modelling approach are required. This paper explores the relation of the approaches to three criteria, namely sustainability concept (see also box), risk perception and eco-efficiency.

A description of the two modelling approaches is given in Section 2. Section 3 highlights the current situation of climate change impacts related to the production of primary and secondary aluminium. Section 4 discusses the two approaches with regard to three different perspectives. It describes what the two approaches tell us with regard to sustainability concepts (Subsection 4.2), risk perception (Subsection 4.3) and eco-efficiency concepts (Subsection 4.4). Conclusions are drawn in Section 5.

\section{Weak and Strong Sustainability}

The sustainability concept has been refined since its general definition by Gro Harlem Brundtland in the late eighties ("Sustainable development is development that meets the needs of the present without compromising the ability of future generations to meet their own needs"). Currently, two distinct degrees of sustainability are used and under debate, namely the weak and the strong sustainability:

weak sustainability: total capital shall remain constant; natural capital stocks can be diminished as long as it is compensated by gains in the man-made stock ("substitutability concept").

strong sustainability: natural capital shall be kept constant, independent of man-made capital ("nonsubstitutability concept").

\section{Description of the Concepts: Recycled Content and End of Life Recycling}

\subsection{Recycled content or cut-off approach}

The recycled content approach considers the share of recycled material (metal) in the manufacture of a product. The environmental impacts of extraction, beneficiation and refining of primary metal are attributed to the first use of that metal product (see Figure 1). The second use of the metal bears the environmental impacts of collection, beneficiation and refining of scrap. Secondary metals do not bear any environmental load from the primary metal production activities.

\subsection{End of Life Recycling or avoided burden approach}

The end of life recycling approach considers the end of life fate of the metal. The share of metal recycled after the use phase of a product determines the amount of primary metal that is not required to be replaced by primary metal feedstock. In short, post consumer recycling avoids primary metal production. The environmental impacts of the avoided primary metal production are credited to the product that sends the metal to recycling (see Figure 1). The metal input to the product under analysis always bears the environmental impacts of primary metals production, irrespective of the fact whether or not recycled, secondary feedstock is used in the product. 

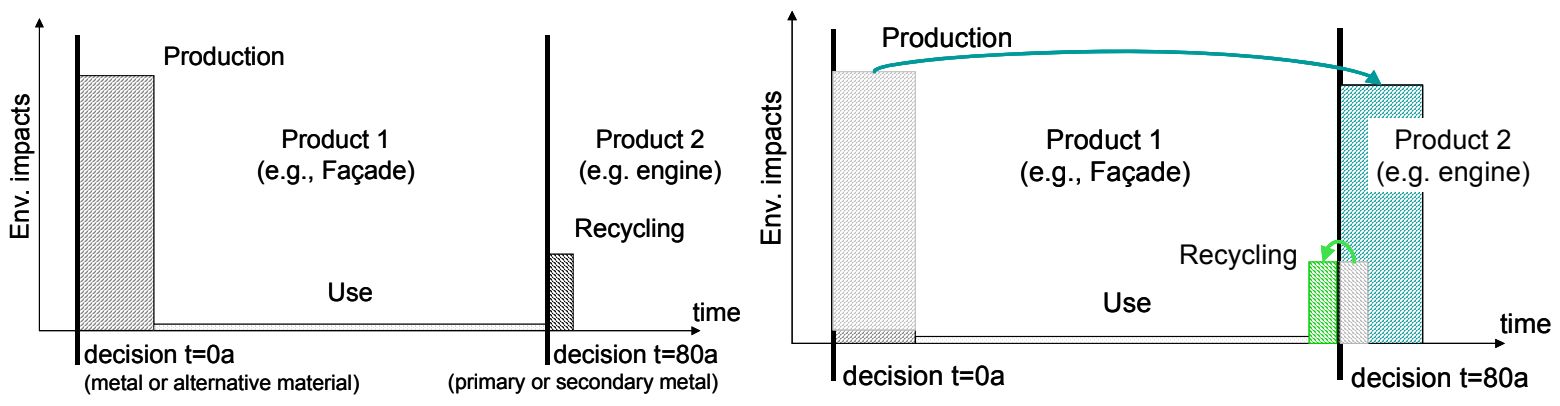

Figure 1: Environmental impacts in the course of time during production, use and end of life (recycling) of a long-living metal product. Left: recycled content approach; Right: end of life recycling approach

\section{Case study: Current Climate Change Emissions of Aluminium Manufacture}

This section describes the emission situation with regard to climate change of the production of primary and secondary aluminium. In the year 2003, the production of primary Aluminium was about 27.4 million tons (MARTCHEK 2006). In the same year, some 23 million tons of new and internal (so-called prompt) scrap and 7 million tons of old (post-consumer) scrap was produced and recycled. If we combine these flows with the climate change impact of primary and secondary aluminium from new and old scrap (11'800, 410, and 1'300 kg CO 2 -eq per ton of primary, new scrap and old scrap aluminium, (ECOINVENT CENTRE 2006), based on (EAA $2000)$ ), the actual annual climate change impact of primary and secondary aluminium production is 320 million tons of $\mathrm{CO}_{2}$-eq and 20 million tons of $\mathrm{CO}_{2}$-eq, respectively.

Each year, society gets a man-made capital of concentrated aluminium of 27.4 million tons at the expense of 320 million tons of $\mathrm{CO}_{2}$-eq.

Industry expert project that the world aluminium stock will increase by $77 \%$ from 520 million tons in 2003 to 920 million tons in 2020 . The primary production is expected to raise to some 38 million tons of primary aluminium (compared to 27.4 million tons in 2003). At the same time the global recycled metal supply to industry will raise to some 13 million tons per year. The recycling rate (post consumer recycled aluminium related to primary plus secondary production from post consumer scrap) is raised from $20 \%$ in 2003 to $25 \%$ in 2020, which is far from a closed loop reality with $100 \%$ recycling feed.

\section{Intent of the two approaches}

\subsection{Introduction}

The two modelling approaches described in Section 2 differ in the LCI results and thus in the conclusions drawn from LCA studies applying one or the other approach. The choice of one or the other approach can be the consequence of the particular goal of an LCA study. For instance the material of a product is chosen (metal) but different product options exist. The end of life recycling approach may then help to identify whether or not product options with a high recyclability are environmentally advantageous. When it comes to more general questions such as "which material to use in a product that provides a certain function", both modelling approaches claim to provide the ideal support. Hence, a goal dependent selection of the appropriate LCl model does not help. 
The following three subsections try to characterise the two concepts from three different perspectives. They are intended to help to structure the discussion and to facilitate an informed choice for one or the other approach.

\subsection{Which Sustainability concept do they serve?}

According to the end of life recycling (or avoided burden) approach, the metal that will probably be recycled in the future results in avoiding primary metals production. Avoiding primary production avoids substantial emissions as is shown in Section 3 with the aluminium example. Attributing these avoided emissions to the product that delivers the scrap for recycling reduces its environmental impacts substantially. The concentrated metal in the product, that is potentially recycled in the future (after its service life ended), is considered equivalent to the natural capital represented by a credit of avoided environmental burdens such as avoided climate change impacts. Thus, the end of life recycling approach is representing the weak sustainability concept (see box).

The recycled content (or cut-off) approach accounts for the environmental impacts at the time they occur. If a product is made of primary metal, the environmental impacts of primary metal production are attributed to this product. No credits are given in case the metal in the product might be recycled in the future (when its service life ended). This modelling approach is very much in line with the strong sustainability concept, where natural capital (climate change credits) is not replaceable by man-made capital (concentrated aluminium).

We learn from this that we cannot claim one approach being the correct one in terms of natural sciences. They are both sensible within their respective value system. At the same time it becomes clear that there is little chance but also no need for a compromise between the two modelling approaches.

\subsection{Which risk perception do they represent?}

Metals are not only used in short-living consumer goods such as packaging but also in longliving products such as wall claddings, steel beams, airplanes and cars. The long duration between the manufacture of such products and their potential recycling makes the modelling of their life cycle distinctly different from short-living products such as beverage cans.

The end of life recycling approach grants credits to metal recycling that may occur in ten, twenty or more years from now (in the case of metals used in buildings this can easily be forty years and more). This approach assumes that the metal will still be in demand by that time in the future. However, this is an assumption and cannot be taken for granted. This means that an environmental loan is borrowed from future generations. The risk of not being able or not being ready ${ }^{1}$ to pay back the environmental credit in the future is taken deliberately. Thus the approach may be classified as risk tolerant or risk seeking.

The recycled content approach promptly accounts for those environmental impacts that are caused by the consumption of primary metals feedstock, disregarding the fact whether or not the product may be recycled in the future. The time frame within which recycling is likely to happen is considered too long to be able to make sufficiently reliable forecasts. The risk of

\footnotetext{
${ }^{1}$ Future generations may argue with the sunk cost argument, that the emissions to manufacture primary aluminium happened in the past and can no more be influenced. Hence, there is no reason to take past emissions into considerations in their decisions.
} 
accepting an environmental credit from future generations is not taken, representing a risk aversive mindset.

With regard to risk perception, the two approaches serve distinctly different views. Similar to the large differences in sustainability concepts supported by the two approaches, a compromise with regard to risk perception seems to be hard to find.

\subsection{What is the message of eco-efficiency considerations?}

The eco-efficiency concept relates environmental impacts caused by an industrial activity to the economic value added by this activity. The eco-efficiency of an entire supply chain of a material can be characterised with the environmental impacts caused up to a certain point in the value chain related to the price of the material at the same point.

Let us have a look at the current prices and climate change impacts of primary and secondary aluminium (see Table 1). The prices represent the average values of primary and secondary aluminium at the London Metals Exchange between November 2002 and March 2003 and the average value of bulk scrap at a building decommissioning site in the city of Zurich during the same period.

The "avoided burden" prices and emissions are calculated on the basis of a $90 \%$ recycling efficiency. For the sake of simplicity the $10 \%$ cover the loss in material quality and the material loss is neglected. The following formula are applied:

$$
\begin{aligned}
& P_{\text {primary, avoided burden (secondary) }}=(1-0.9) * P_{\text {primary }}+0.9 * P_{\text {secondary }} \\
& P_{\text {primary, avoided burden (scrap) }}=(1-0.9) * P_{\text {primary }}+0.9 * P_{\text {scrap}} ; \\
& P_{\text {secondary, avoided burden }}=(0.9) * P_{\text {primary }}+(1-0.9) * P_{\text {secondary; }} \\
& P_{\text {scrap, avoided burden }}=(0.9) * P_{\text {primary }}+(1-0.9) * P_{\text {scrap }}
\end{aligned}
$$

with $\mathrm{P}$ being price, and climate change impact, respectively.

We observe that the "avoided burden" prices and environmental impacts of primary aluminium are substantially reduced. The prices and climate change impacts of secondary aluminium and scrap are much higher at the same time.

In a next step the eco-efficiency of the three metals (primary, secondary and scrap) is calculated by dividing the climate change impact by the product price. It shows that primary aluminium shows the highest emissions per US-\$, whereas aluminium scrap shows the lowest value, applying the recycled content approach. When applying the end of life recycling approach the picture turns. Scrap, modelled according to the avoided burden approach shows the highest emissions per US-\$ whereas primary aluminium credited with the recycled secondary aluminium emits the lowest amount per $\mathrm{kg}$.

In other words: the manufacture of sorted aluminium scrap and the manufacture of secondary aluminium shows the highest eco-efficiency applying the recycled content approach whereas primary aluminium production shows the highest eco-efficiency based on the end of life recycling approach (credits granted for the supply of scrap or secondary aluminium). 


\begin{tabular}{|c|c|c|c|}
\hline Aluminium & price & $\begin{array}{l}\text { climate } \\
\text { change impact }\end{array}$ & eco-efficiency \\
\hline & US-\$/kg & $\mathrm{kg} \mathrm{CO}-\mathrm{eq} / \mathrm{kg}$ & $\mathrm{kg} \mathrm{CO}$-eq/US-\$ \\
\hline \multicolumn{4}{|l|}{ Recycled Content Approach } \\
\hline primary & 1.40 & 11.8 & 8.43 \\
\hline secondary & 1.35 & 1.3 & 0.96 \\
\hline scrap & 0.76 & 0.41 & 0.54 \\
\hline \multicolumn{4}{|l|}{ End of Life Recycling Approach } \\
\hline primary, avoided burden (secondary) & 1.355 & 2.35 & 1.73 \\
\hline primary, avoided burden (scrap) & 0.824 & 1.55 & 1.88 \\
\hline secondary, avoided burden & 1.395 & 10.8 & 7.71 \\
\hline scrap, avoided burden & 1.336 & 10.7 & 7.98 \\
\hline
\end{tabular}

Table 1: Price, climate change impacts (cradle to gate) and eco-efficiency factors of primary, secondary and scrap aluminium according to the two approaches discussed in this paper

In case of long-living products such as façade claddings and the like, the economic value of secondary aluminium applied in this simplified calculation is an upper bound value. Economic discounting would result in much lower values: Assuming 40 years life time and an net interest rate of $5 \%$ results in a discounted value of $14 \%$ of today's price. With such discounted economic figures the difference between the eco-efficiency of primary, secondary and scrap aluminium is diminished. But the principle differences between the materials and between the approaches remain the same.

\section{Conclusions}

The debate on the correct or appropriate approach regarding the modelling of recycling cannot be solved by natural science only. Differences in values, views of the world and cultural perspectives influence the way recycling is modelled. This paper highlights differences of the approaches with regard to three aspects:

The end of life recycling approach is in line with the weak sustainability concept, where natural capital can be substituted by man made capital. It supports risk seeking attitude by borrowing environmental loans from future generations for man made capital potentially being reused or recycled in the future. It results in a distinctly higher eco-efficiency of primary aluminium that is predicted to be recycled in the future as compared to secondary aluminium.

The recycled content approach is in line with the strong sustainability concept, where natural capital must not be substituted by man made capital and thus environmental impacts are strictly linked to the product (man made capital) that causes them, irrespective of any potential future use of it. The approach supports a risk aversive attitude in that emissions occurring today are attributed to today's product and no burden shifting to future generations occurs. Finally the eco-efficiency of recycling aluminium is substantially higher as compared to the production of aluminium from bauxite. 


\begin{tabular}{|l|c|c|}
\hline & $\begin{array}{c}\text { "end of life } \\
\text { recycling" or } \\
\text { "avoided burden" }\end{array}$ & $\begin{array}{c}\text { "recycled } \\
\text { content" or } \\
\text { "cut-off" }\end{array}$ \\
\hline Future utility & yes & uncertain \\
\hline Sustainability concept & weak & strong \\
\hline Environmental grants from future generations & yes & no \\
\hline Shift of burdens into future & yes & no \\
\hline Risk perception & risk seeking & risk aversive \\
\hline Eco-efficiency primary versus secondary metal & $\begin{array}{c}\text { primary > } \\
\text { secondary }\end{array}$ & $\begin{array}{c}\text { secondary > } \\
\text { primary }\end{array}$ \\
\hline
\end{tabular}

Table 2: Synopsis of characteristics of the two modelling approaches of recycling

Further characteristics are listed in Table 2. Depending on the value choices of a commissioner, the LCA of metal containing products may thus look very different. Whereas metal industry may well endorse the end of life recycling approach and by that follow the weak sustainability concept and adopt a risk seeking strategy, national authorities may be indebted to long-term welfare and environmental protection and thus may rather follow the strong sustainability concept and act rather risk aversive. National authorities may therefore tend to apply the recycled content approach.

Because of the involvement of value judgements and preferences in the modelling of recycling of materials it is unlikely that a consensus will ever be found. There is even no need to reach consensus with this respect. However, we need clear statements from (public or private) commissioners of LCA study on their preferences with regard to the sustainability concept and risk perceptions to derive the adequate modelling of recycling. Additionally, transparent unit process life cycle inventory data are needed by the practitioner to be able to adjust the modelling to the value choices of the commissioner, if necessary. This freedom of choice is necessary in open, democratic and pluralistic societies. The ecoinvent database (ECOINVENT CENTRE 2006) is one of the few LCl databases worldwide that provides this flexibility.

\section{References}

ANONYMOUS 2006: "Declaration by the Metals Industry on Recycling Principles." In Int J LCA Vol. 12 (1): 59-60.

EAA 2000: Environmental profile report for the European aluminium industry April 2000. European Aluminium Association, Brussels.

ECOINVENT CENTRE 2006: ecoinvent data v1.3, Final ecoinvent reports No. 1-16. CD-ROM ISBN 3-905594-38-2, Swiss Centre for Life Cycle Inventories, from www.ecoinvent.org, Duebendorf, Switzerland.

Ekvall, T. \& WeidemA, B. 2004: "System Boundaries and Input Data in Consequential Life Cycle Inventory Analysis." In Int J LCA Vol. 9 (3): 161-171, www.scientificjournals.com/sj/lca/welcome.htm.

FRISCHKNECHT, R. 2000: "Allocation in Life Cycle Inventory Analysis for Joint Production." In International Journal of Life Cycle Assessment Vol. 5 (2): 85-95.

FRISCHKNECHT, R. 2006: "Notions on the Design and Use of an Ideal Regional or Global LCA Database." In Int J LCA Vol. 11 (Special Issue 1): 40-48. 
KIM, S., HWANG, T., LEE, K.-M. 1997: “Allocation for Cascade Recycling System.” In Int J LCA Vol. 4 (2): $217-222$.

KLÖPFFER, W. 1996: "Allocation Rule for Open-Loop Recycling in Life Cycle Assessment - A Review." In Int J LCA Vol. 1 (1): 27-31.

MARTCHEK, K. 2006: “Modelling More Sustainable Aluminium." In Int J LCA Vol. 11 (1): 34-37.

WeIDEMA, B. 2001: "Avoiding co-product allocation in life-cycle assessment." In Journal of Industrial Ecology Vol. 4 (3): 11-33.

WERNER, F. 2002: Interdependencies between LC-modelling and the use of LCA in product design-related decision situations. PhD, ETHZ, Zürich.

Yamada, H., Daigo, I., Matsuno Y., Adachi, Y., Kondo, Y. 2006: "Application of Markov Chain Model to Calculate the Average Number of Times of Use of a Material in Society. An Allocation Methodology for Open-Loop Recycling. Part 1: Methodology Development." In Int J LCA Vol. 11 (5): 354-360. 